\title{
Article
}

\section{The Application of the Latest Technologies for Smart City Construction in China}

\author{
Yufang Huang ${ }^{1}$, Hongtao Peng ${ }^{2}$, Aocheng Zhong ${ }^{3}$, Zhiyuan Zhou ${ }^{4}$, Massoud Sofi ${ }^{5}$, Tingyan \\ Xing ${ }^{6}$ and Guoxin Ma ${ }^{7}$ \\ 1 Yufang Huang, Senior Engineer, Ph.D. candidate, MEng (civil), Faculty of Information Engineering, China, \\ University of Geosciences, Beijing 100083, China \\ 2 Hongtao Peng, Associate Professor, Ph.D., College of Water Resources and Civil Engineering, China \\ Agricultural University, Beijing 100083, PR China \\ 3 Aocheng Zhong, Ph.D. candidate, MEng (civil), Department of Infrastructure Engineering, University of \\ Melbourne, Parkville, VIC, Australia, 3010 \\ 4 Zhiyuan Zhou, Ph.D. candidate, MEng (Civil), Department of Infrastructure Engineering, University of \\ Melbourne, Parkville, VIC, Australia, 3010 \\ 5 Massoud Sofi, research fellow, Department of Infrastructure Engineering, University of Melbourne, \\ Parkville, VIC, Australia, 3010 \\ 6 Tingyan Xing, Vice Professor, Ph.D., Faculty of Information Engineering, China University of Geosciences, \\ Beijing 100083, China \\ 7 Guoxing Ma, BEng (civil), College of Water Resources and Civil Engineering, China Agricultural \\ University, Beijing 100083, PR China \\ * Correspondence: pwb@cau.edu.cn; Tel.: +86 13671124965 \\ Received: date; Accepted: date; Published: date
}

\begin{abstract}
With the continuous emergence and application of new technologies, the construction of smart cities has entered the practical promotion period. Since 2012, the pilot construction of smart city has been promoted by the government in China. On the basis of these practical experiences, this paper presents an overview of the latest technologies and applications for smart city construction in China and demonstrates that smart city strategy needs to be implemented according to local conditions, adhering to the people-oriented concept and using scientific and effective top-level design and planning. The construction of smart city is comprehensive system engineering, including the integration of geographic information sharing service platform, full-cycle management and control system of urban planning, construction and social management, as well as intelligent business information management system of gardening, water conservancy, environmental protection and other industries and departments. The information system (GIS), satellite remote sensing (SRS), global navigation satellite system (GNSS), Internet of things, mobile applications, cloud computing, visualization technology ware used to promote urban construction and sustainable development, and to meet the needs of future smart city development. Results show that centralized management is very important for the construction of smart city. The government plays a major role in the construction of smart city, which will be conducive to the development of new technologies and the effective use of smart city construction resources.
\end{abstract}

Keywords: Information technology; Infrastructure planning; Town \& city planning; Municipal \& public service engineering; Smart city

\section{Introduction}

At present, more than half of the world's population resides in urban areas. It is projected that more than two-thirds of people around the world will live in cities by 2050 [1]. China's economic and social development is accompanied by growing urbanization. By 2020, the urbanization rate of the population in China is expected to reach $60 \%$, and the urbanization rate of the registered population is expected to reach $45 \%$ [2]. An increase in population puts pressure on the management of information, transportation infrastructure, urban environment, resources needed to support the urbanization and security. These together with such a significant increase in the flow of goods, 
information and services have caused difficulties in the development of cities and towns [3, 4]. Some countries have strategically designed the superior design of smart cities. For example, Seoul has released the "Smart Seoul 2015" plan (The Seoul government released its plan for a smart city in the future in 2011). Amsterdam in the Netherlands hopes to use the "Smart City" (Amsterdam Smart City; ASC) to improve the living standards of the public and create new employment opportunities [5]. Smart City is a new model that strengthens urban planning, construction, and management by comprehensively applying modern science and technology, integrating information resources, and coordinating business application systems.

In order to build a smart city, it is necessary to establish the integration mechanism of virtual and real mapping and real-time interaction between physical city and digital city [6]. Realizing a proper real-time digital twin is the condition of building a smart city. The benefits are numerous. It adds to the efficiency of the information, the efficiency of the people, logistics and the safety experience of cities [7, 8]. The Ministry of Housing and Urban-Rural Construction of the People's Republic of China initiated several national smart cities pilot projects in 2012 to explore a systematic approach towards developing, operating, managing and serving smart cities. In the process of developing smart cities, it is necessary to rely on new technologies in the fields of information and communication technology and the internet to realize a comprehensive integration of urban management, extensive number interconnection between various systems, efficient analysis of data and intelligent processing technologies [5]. This paper reports the application of the latest technologies intended for smart city development in China. It aims to be a reference source for others wanting to use new technologies to promote the construction and development of smart cities.

\section{Developing multi-industry, multi-department intelligent business information management system}

To achieve the effective integration and utilization of information resources, it is necessary to make a multi-industry and multi-department (MI \& MD) smart business information management system. The value chain brought by MI \& MD intelligent business information management system to the city is shown in Figure 1.

To build a complex giant system that maps and interacts with the urban physical features and forms a virtual digital twin city, a base map which reflects the real-world needs to be built using tools such as satellite remote sensing (SRS), geographic information system (GIS) and global navigation satellite system (GNSS). The GIS cloud service platform provides cloud services for aerospace remote sensing image maps, topographic maps, electronic maps, and other geographic information data. Secondly, it establishes a mechanism for sharing and exchanging information resources for the local government, such as planning, construction, water distribution, and drainage, transportation infrastructure. Therefore, MI \& MD smart business information management system serves government management, business, and public life. Based on the effective integration of urban planning management information, unified, complete, and standardized comprehensive database of the map is established to achieve "finish one blueprint." The big data and artificial intelligence technology are used to plan and construct the big data analysis system, improve planning management efficiency, and provide technical support for urban government decision-making. Thirdly, for the government supervision and management of the construction process after the approval of the planning permit, quality assurance, safety supervision system, environmental supervision system, personnel management system, and construction engineering, a cooperative supervision system is established, respectively. The system will be used for equipment monitoring, dust and noise control, face recognition, intelligent safety and other processes in the construction site. It strengthens the information-based supervision of the quality, logistics, safety, 
environment, and personnel of construction projects. It can also be used to promote green civil construction and create a good order in the construction market. In addition to planning, construction, management, and services, the management system of smart cities also integrates smart information systems such as intelligent maintenance of parks, water drainage, environmental maintenance, railways, and the management needs of other related industries.

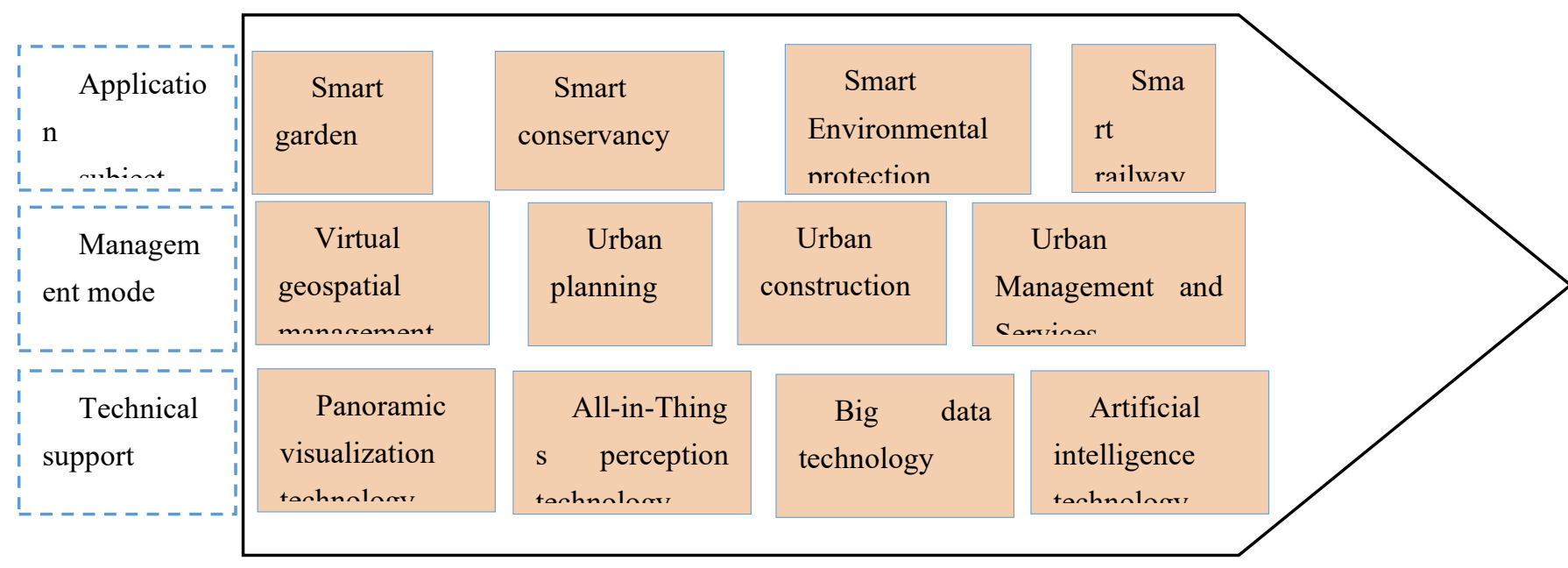

Figure 1. MI \& MD smart business information management system

The realization of the smart city is to comprehensively use the new generation of information technology, such as the Internet of Things (IoT), cloud computing, big data, and spatial geographic information integration, to improve the efficiency of urban operation, to implement new ideas. It also uses modes of intelligent urban planning, construction management, and service to create better urban working and living conditions for citizens. The smart city technology application integration framework is shown in Figure 2. The existing city organizational structures are based on the concept of specialization of urban management. New York City, for example, already had in place many digital assets that were running on different platforms across various city agencies. If urban development is in an era of austerity and limited public funds, it is feasible to construct smart cities selectively. For instance, Amsterdam chose the energy and open data (A digital space created by the Dutch government for environmental protection and energy conservation) [9]. The application of new information technology can only provide technical solutions that make smart city management structure more holistic and comprehensive. 


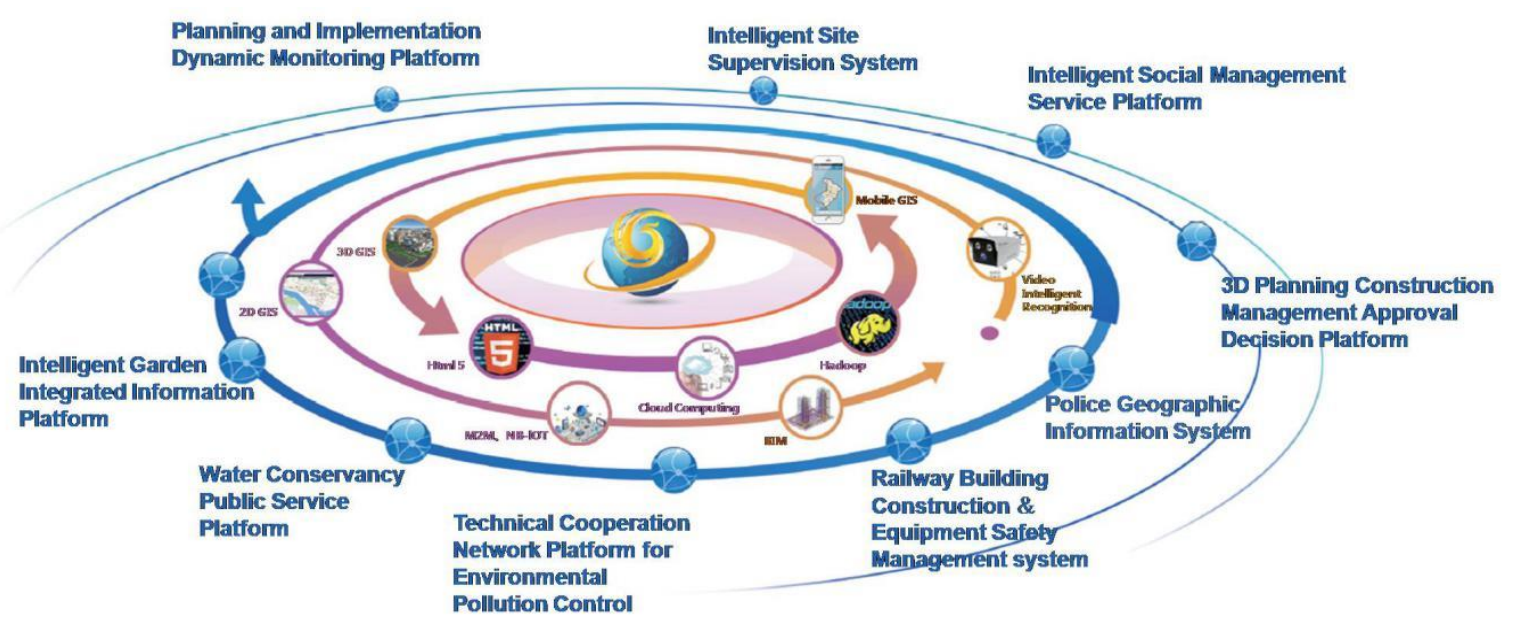

Figure 2. Technology application integration framework

\section{Geographic Information Sharing Service Platform}

The geographic information sharing platform is mainly dedicated to the development of a unified, multi-source, massive basic geographic data (topographic map, image map, digital elevation model, place name address, etc. ) management, updating, and sharing software system. The platform integrates massive network spatial information sharing, service management, background log monitoring, and resource display applications, and provides efficient, safe and reliable Spatio-temporal integrated data application services for all departments.

\subsection{Geospatial data database}

As a framework of urban information resources integration, information resources sharing and application model based on "one map" has unique advantages. In this way, the urban geospatial data can be integrated with the professional data of various departments, and the effective integration of regional information resources can be realized and allow for the delivery of visualized decision making processes and data sharing services to the government. Developing the application of government affairs and public services on the "one map" can avoid duplication of construction and waste of funds, so as to better exert the economic and social benefits of the funds invested. 
The "one map" integration model of urban information resources is shown in Figure 3.

\section{One map area management and data integration}

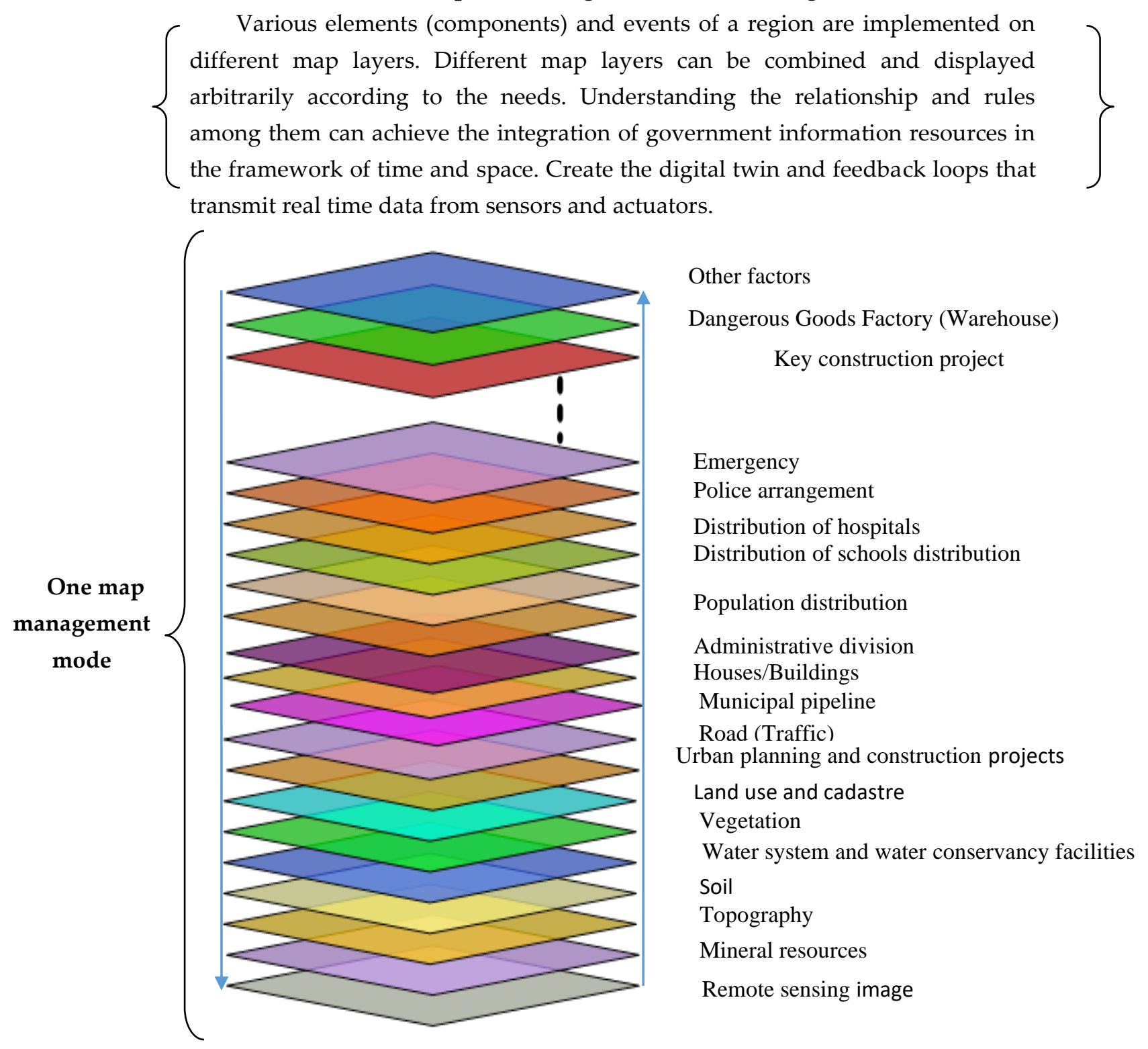

Figure 3. Schematic map of "One Map" integration model of urban information resources

Geospatial data is particularly important as a fundamental base map data in the "one map" integration model of urban information resources. The framework architecture of urban geospatial data consists of four levels:

First, the space benchmark includes planar coordinate system, height datum, and GPS Continuously Operating Reference Stations (CORS) and specifies the plane coordinates and height datum of the entire geospatial library.

Second, historical archives include image data history base, basic geographic data history base, planning thematic archives, comprehensive underground pipeline archives, thematic data archives, etc.

Third, the current database reflects the status quo of the city, which is divided into the current geographical situation and the management status, each of which contains many sub-categories. 
Fourth, the planning information base reflects the future development prospects of the city, which is divided into general planning, zoning planning, controlled detailed planning, special planning, and planning scheme. The entire geospatial data framework includes geospatial positioning benchmarks, representing past, present, and future geographic data, forming a comprehensive database that comprehensively reflects urban development changes. The urban geospatial data system framework is shown in Table 1.

Table 1 Urban geospatial data system framework

\begin{tabular}{|c|c|c|c|c|c|c|}
\hline \multicolumn{2}{|c|}{ Planning } & $\begin{array}{l}\text { General } \\
\text { planning }\end{array}$ & $\begin{array}{l}\text { Zoning } \\
\text { planning }\end{array}$ & $\begin{array}{l}\text { Controllab } \\
\text { le detailed } \\
\text { planning }\end{array}$ & $\begin{array}{l}\text { Special } \\
\text { planning }\end{array}$ & $\begin{array}{l}\text { Planni } \\
\text { ng } \\
\text { scheme }\end{array}$ \\
\hline \multirow{2}{*}{$\begin{array}{l}\text { Current } \\
\text { database }\end{array}$} & $\begin{array}{l}\text { Managem } \\
\text { ent status }\end{array}$ & $\begin{array}{c}\text { Traffic } \\
\text { subject data }\end{array}$ & $\begin{array}{l}\quad \text { Plannin } \\
\mathrm{g} \quad \text { subject } \\
\text { data }\end{array}$ & $\begin{array}{c}\text { Library } \\
\text { subject data }\end{array}$ & $\begin{array}{c}\text { Traffic } \\
\text { subject data }\end{array}$ & $\begin{array}{l}\text { Other } \\
\text { subject } \\
\text { data }\end{array}$ \\
\hline & $\begin{array}{l}\text { Current } \\
\text { geographical } \\
\text { situation }\end{array}$ & $\begin{array}{c}\text { Image } \\
\text { map base }\end{array}$ & $\begin{array}{l}\text { 3-D } \\
\text { Geographic } \\
\text { database }\end{array}$ & $\begin{array}{l}\text { Electronic } \\
\text { map base }\end{array}$ & $\begin{array}{c}\text { 3-D Street } \\
\text { View Database }\end{array}$ & $\begin{array}{l}\quad \text { Digital } \\
\text { elevation } \\
\text { model } \\
\text { base }\end{array}$ \\
\hline \multicolumn{2}{|c|}{ Historical archives } & $\begin{array}{l}\text { Image } \\
\text { data history } \\
\text { base }\end{array}$ & \begin{tabular}{l}
\multicolumn{1}{c}{ Basic } \\
geographic \\
data \\
history \\
base
\end{tabular} & $\begin{array}{l}\text { Planning } \\
\text { thematic } \\
\text { archives }\end{array}$ & $\begin{array}{l}\text { Comprehensi } \\
\text { ve underground } \\
\text { pipeline } \\
\text { archives }\end{array}$ & $\begin{array}{l}\text { Thema } \\
\text { tic data } \\
\text { archives }\end{array}$ \\
\hline \multicolumn{2}{|c|}{ Space benchmark } & $\begin{array}{l}\quad \text { Planar } \\
\text { coordinate } \\
\text { system }\end{array}$ & $\begin{array}{l}\text { Height } \\
\text { datum }\end{array}$ & \multicolumn{2}{|c|}{$\begin{array}{l}\text { GPS Continuously Operating } \\
\text { Stations }\end{array}$} & Reference \\
\hline
\end{tabular}

\subsection{Establishment of urban geographic information sharing service platform}

The geographic information sharing service platform is one of the core infrastructures of smart cities. The urban geographic information sharing service platform will realize the management and service of multi-source and massive geographic information resources. Through the interface specification of spatial data interoperability developed by the Open Geospatial Consortium (OGC), the data interoperability of heterogeneous GIS platforms will be realized to meet the requirements of the development and sharing of geographic information resources. The platform consists of four parts: data sharing service subsystem, resource display subsystem, database management subsystem, and operation and maintenance support subsystem. It integrates functions such as massive data management, network space information sharing, service management, background $\log$ monitoring, and resource display application in one body. The sketch of the geographic information sharing service platform is shown in Figure 4. 


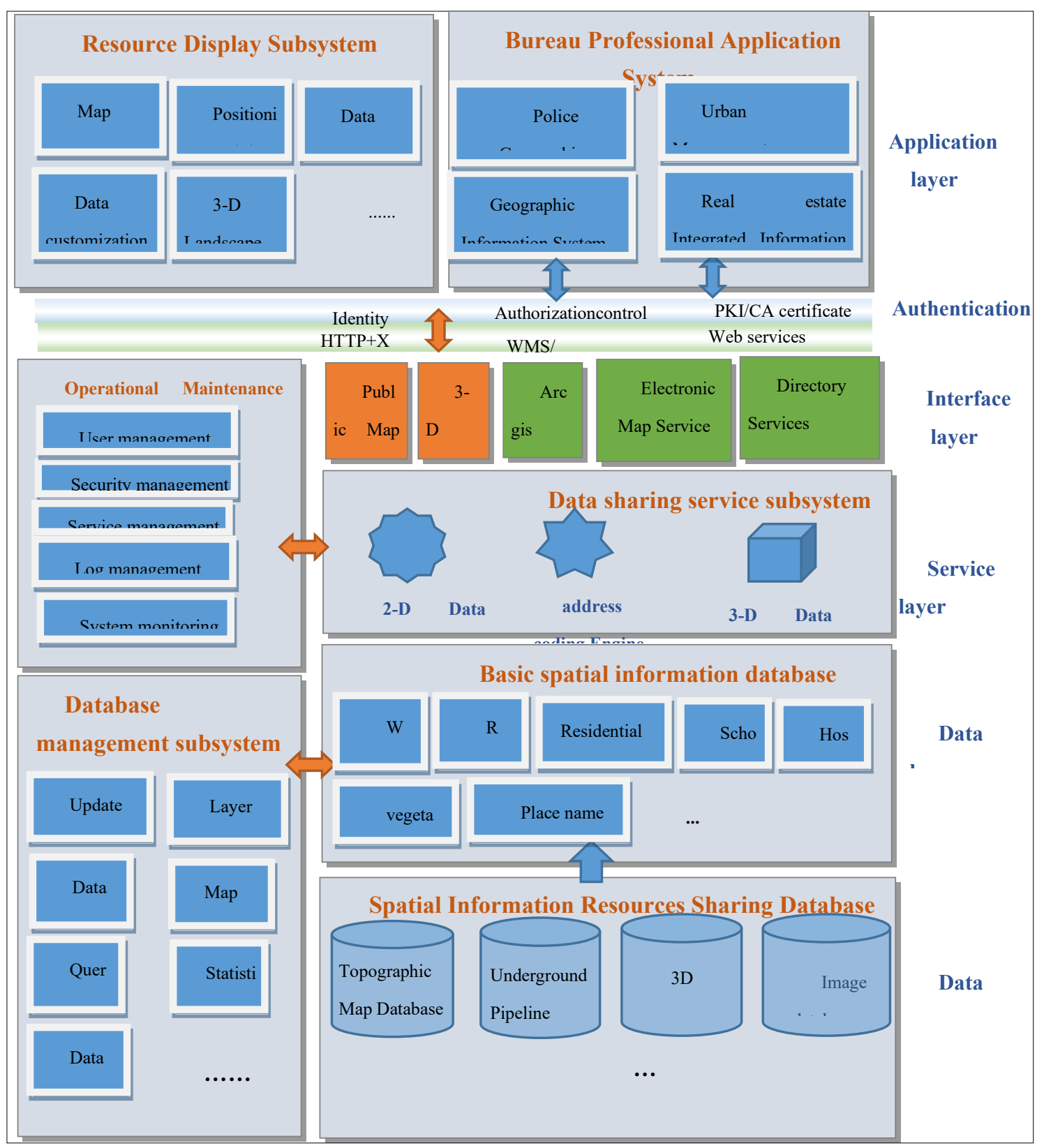

Figure 4. Sketch of geographic information sharing service platform

\section{Smart Planning Management}

Smart planning management is supported by the compilation, approval, supervision, decision-making, and publicity of urban planning, focusing on the "one map for planning", it establishes an integrated planning database including urban status data, planning results, planning approval data, planning supervision data and planning publicity data. The planning integrated application software system includes information sharing, intelligent decision-making, vertical and horizontal linkage, business collaboration and mobile interconnection, etc. It can help form a new planning and management mode of scientific, fine management, smooth collaboration, intelligent decision-making, promoting the multi-dimensional integration of urban planning and quantitative, intelligent and multi-dimensional visualization of information management gradually. 


\section{1 “One Map" planning outcomes management system}

"One Map" planning outcomes management system displays the city's planning results, planning project management data, planning approval data, planning dynamics, planning industry laws and regulations, and many other planning results data, and comprehensively displays the city in the form of maps and comprehensive reports. The system can flexibly realize the positioning of the planning project, the related query of various planning results data, the query of planning approval data, the analysis of various indicators of urban planning land, the composition of various types of land, the construction composition, and the statistical indicators of different areas of the city. Provide flexible, comprehensive and critical data information for urban planning and construction decision-making. At the same time, the system supports access on mobile devices. The project planning approval data query (map, table) is shown in Figure 5.

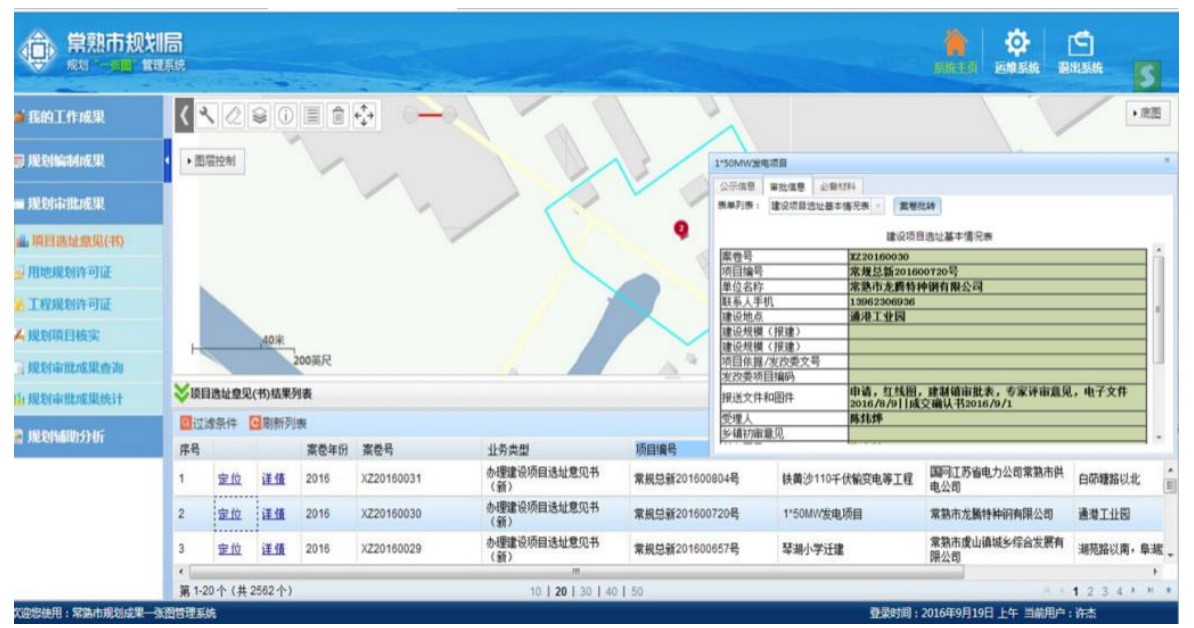

Figure 5. Representation of Project planning approval data query (map, table)

It is necessary for urban social management and service to adapt to planning. The level of urban management service is an important sign and direct reflection of the degree of civilization and the comprehensive strength of a region [10]. The grid urban management model has been widely used in China. It divides the urban space into grids according to a certain scope, relying on information technology and collaborative work mode, realizes the unified and coordinated management of various resources and their management objects in the grid unit, and realizes the coordinated scheduling and sharing of resources among different grids, to build a comprehensive information platform which integrates the management elements of "human, land, material, situation, affairs and organization", to promote the transformation of social management from "rough management" to "fine management", to promote the transition of public service from "scattered service" to "one-stop service".

\subsection{Planning Approval Management System}

The planning approval management system is based on the urban planning management "one book and two certificates" (location proposal, land permit, construction project planning permit) as the mainline, combined with project management process, using advanced information technology such as GIS, MIS, CAD, etc. It includes the planning business approval part and the planning management CAD drawing section. Using the CAD drawing function, a land occupation plan can be created that is related to the project, as shown in Figure 6. The system can complete a series of services, such as receiving, processing, auditing, validating, filing, certification and so on. 


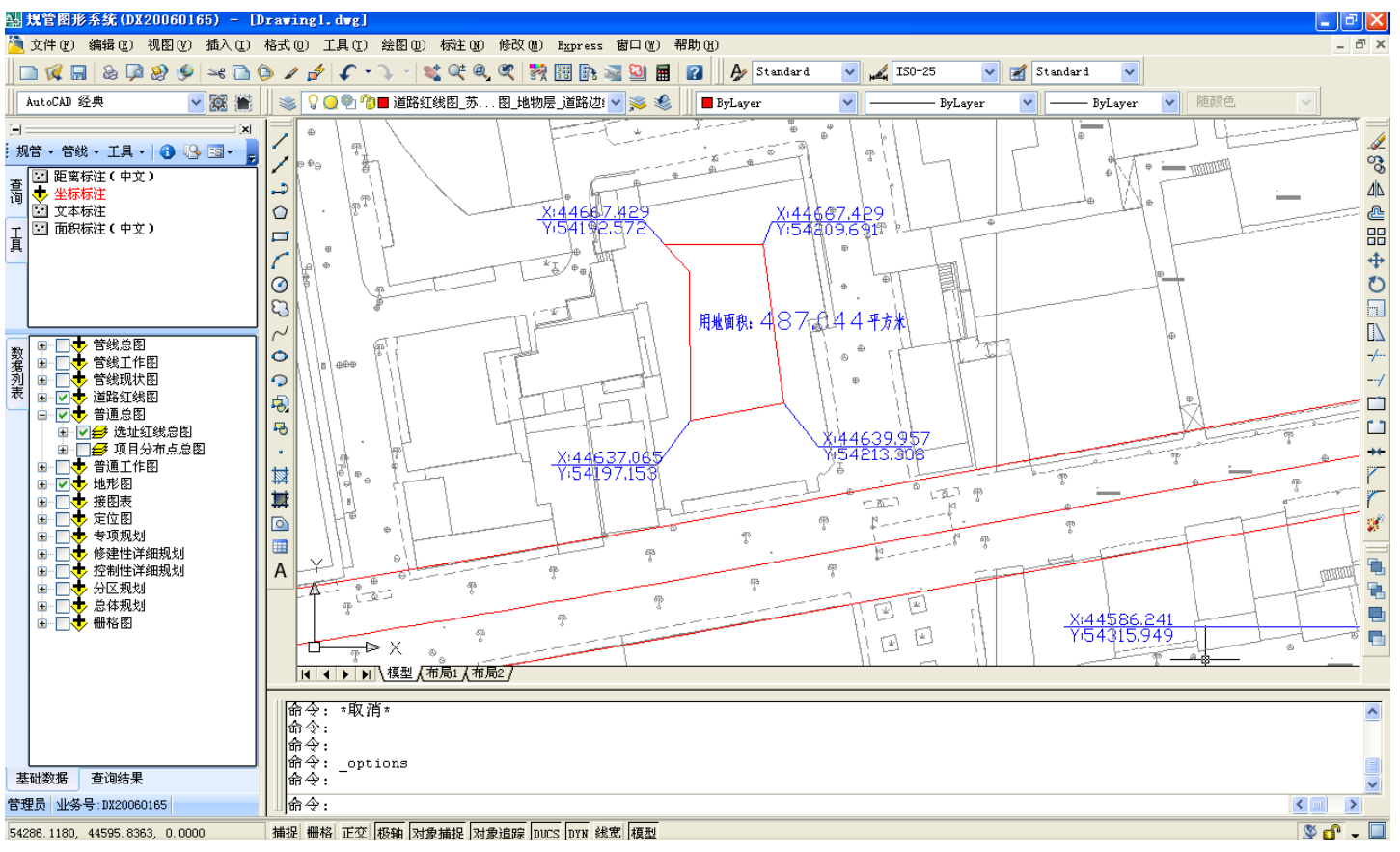

Figure 6. CAD planned land occupation drawing

\subsection{Planning Inspector Management System}

In order to ensure that urban construction strictly abides by urban land and space planning, government management departments often use satellite remote sensing images to quickly obtain spatial information within the city, and make use of the comparison between multi-temporal remote sensing image data and planning results, planning approval data, and current data to timely understand the status of urban development, and find that urban construction is not accord with planning. It also serves urban planning supervision and urban management by means of verification, reporting and statistical analysis. The system can simultaneously call multiple images and synchronize the map window to find urban changes, such as changing from green space to house, as shown in Figure 7. 


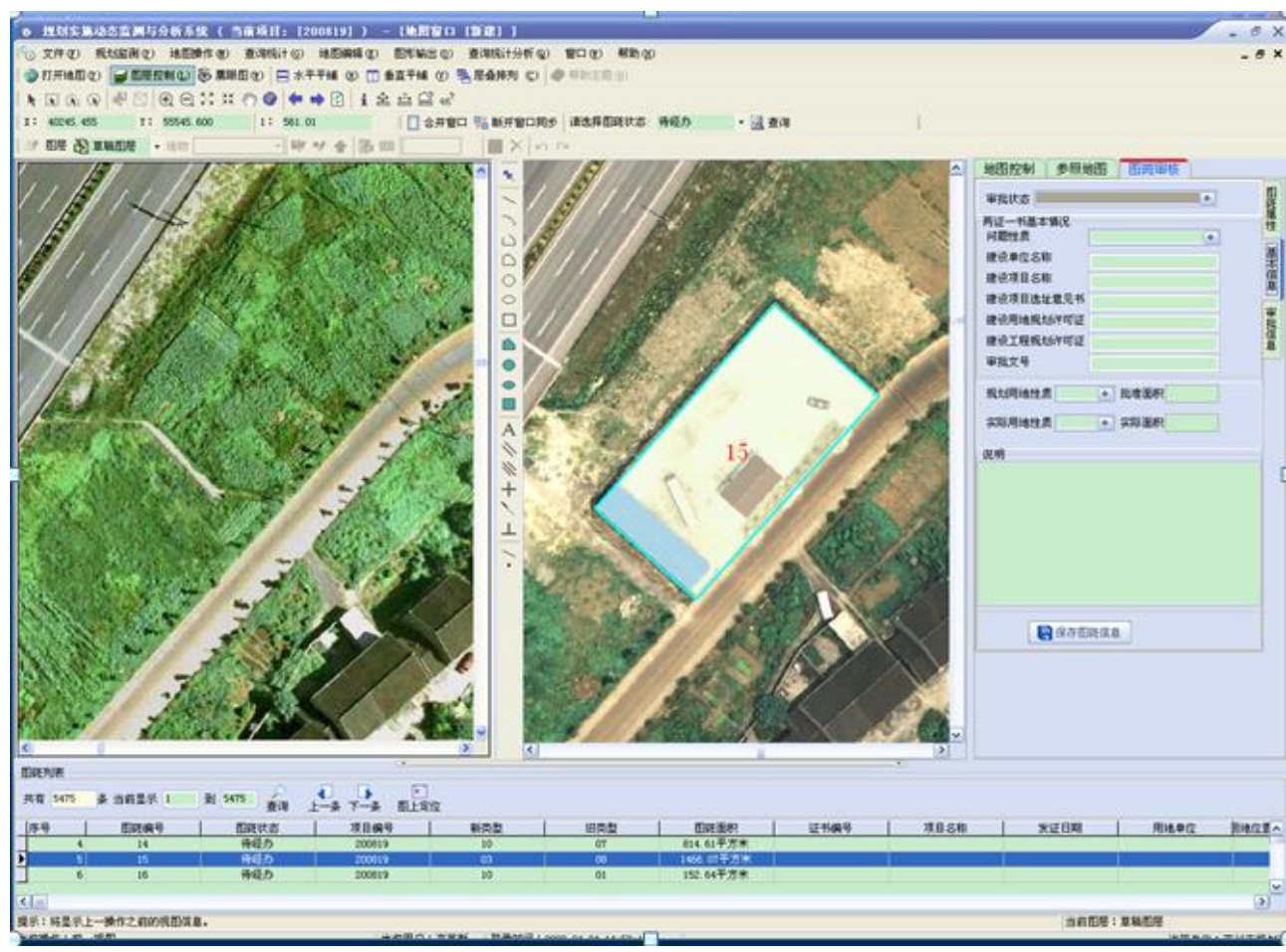

Figure 7. Multi-period images reveal urban changes (from land to houses)

\subsection{Planning big data analysis system and ventilation channel planning construction}

The planning big data analysis system provides functions such as comprehensive query, model definition, status analysis, planning implementation monitoring, and analysis, and will combine the urban traffic and air pollution prevention and other subjects to establish a special analysis model, and obtain thematic analysis results to provide data for government decision-makers. Figure 8 shows the population indicators, land use indicators, green space indicators, industry indicators, and the average progress and ranking of the implementation of each implementation unit (about one township size) based on the analysis model. Urban ventilation channel planning is an important part of urban planning and design to improve and improve urban air pollution and heat island effect. According to the meteorological data of the city, the wind field in the urban area can be simulated by the computer. The technologies such as geographic information system, Computational Fluid Dynamics (CFD ), the local circulation structure research and numerical simulation were used to improve the accuracy and effectiveness of urban ventilation channel planning ( Figure 9). 


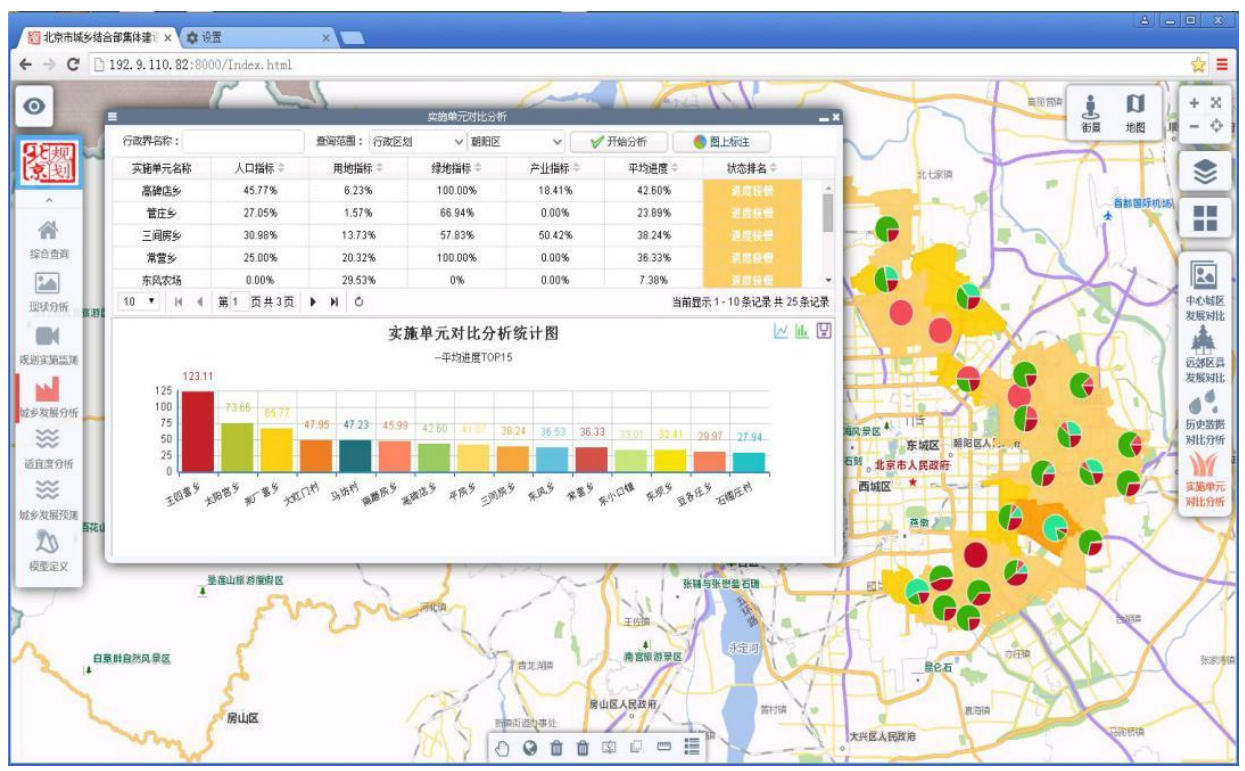

Figure 8. Comparative analysis of different implementation units

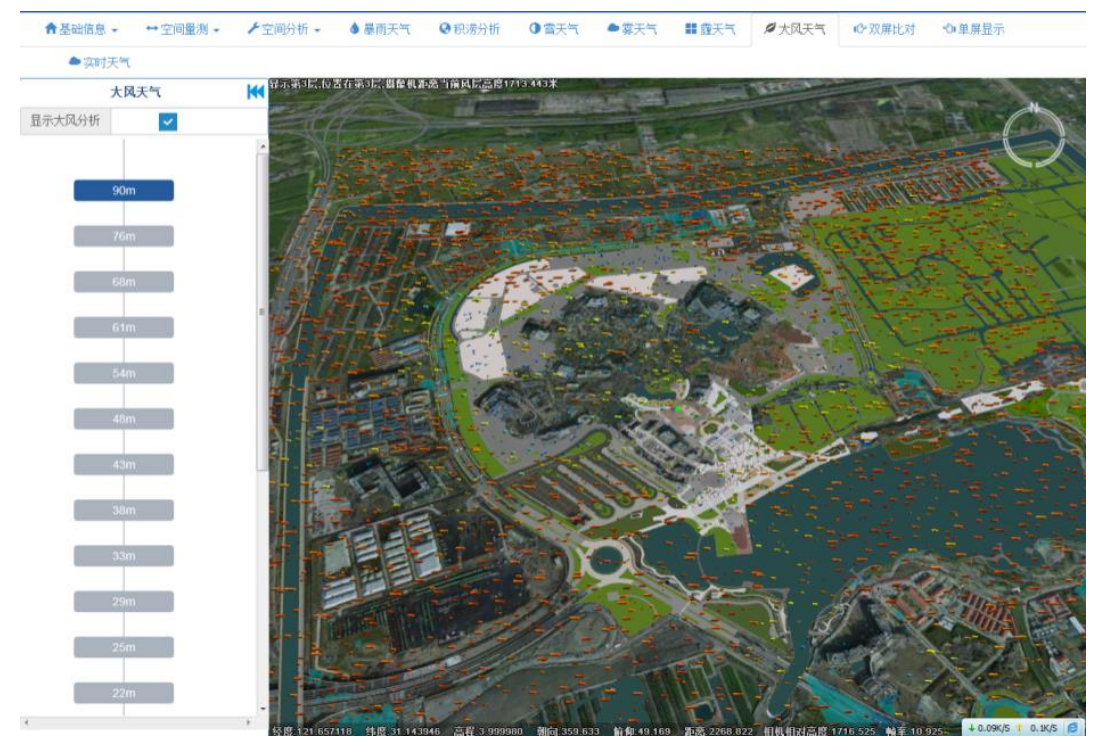

Figure 9. Analysis of wind field and the ventilation channel planning in different height regions of amusement park

\section{Smart construction management}

Smart construction management is to establish a coordinated supervision mechanism, which can form an organic whole for the quality supervision, safety supervision, environmental supervision, employee supervision and video surveillance of urban construction projects, and a closed-loop feedback mechanism for the management of construction site problems [11, 12, 13]. The daily behavior supervision of the construction site, standardize the construction site operation behavior, monitor the project quality and construction safety status, promote green construction, civilized construction, and create a good order in the construction market. The smart construction management information system is shown in Figure 10. 

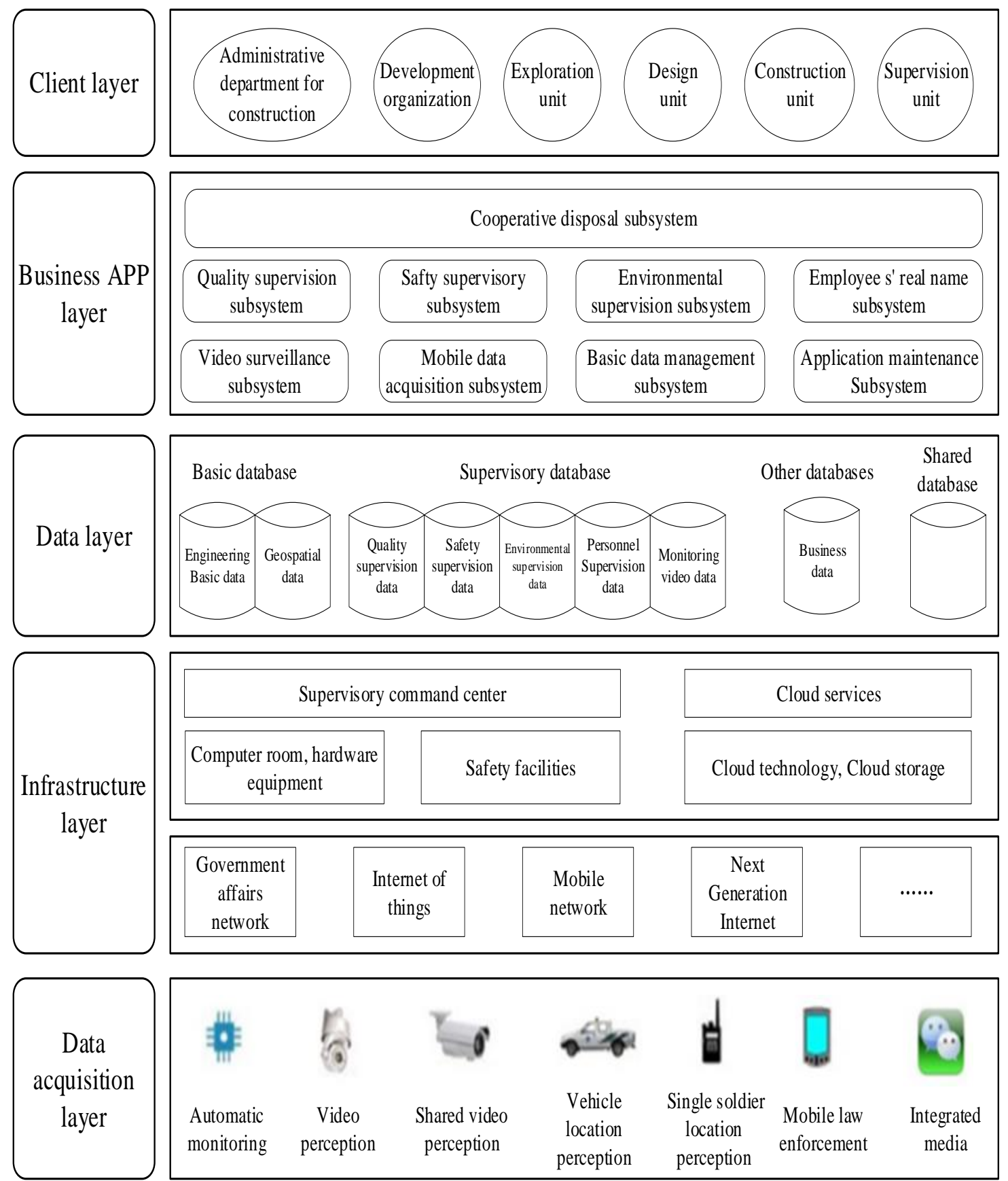

Figure 10. Smart construction management Information System

\section{1 Quality Supervision Subsystem}

At present, the supervision of construction project quality mainly includes the construction materials, the behavior of employees, the key nodes of the construction process, etc. The quality supervision subsystem can realize the effective supervision of the whole process of quality inspection of building materials used at the construction site and the traceability supervision of building materials.

\section{2 Safety Supervision Subsystem}

The safety supervision subsystem can realize the supervision function of the safety state of construction engineering, including the safety behavior supervision of employees, the safety supervision of construction machinery and equipment, the monitoring of dangerous parts, the inspection of equipment and the inspection and acceptance of safety protection related equipment. 
Large and medium construction cranes shall be registered, filed and recorded by the competent construction authorities in accordance with the regulations. At the same time, the system will also incorporate the real-time operation data of the on-site mechanical equipment and the management of real-time operation video data into the system through various sensors, and establish an early warning. The model built for real-time collection and inspection finds hidden dangers and issues early warnings. Figure 11 records the condition monitoring and simulation of the running tower crane.

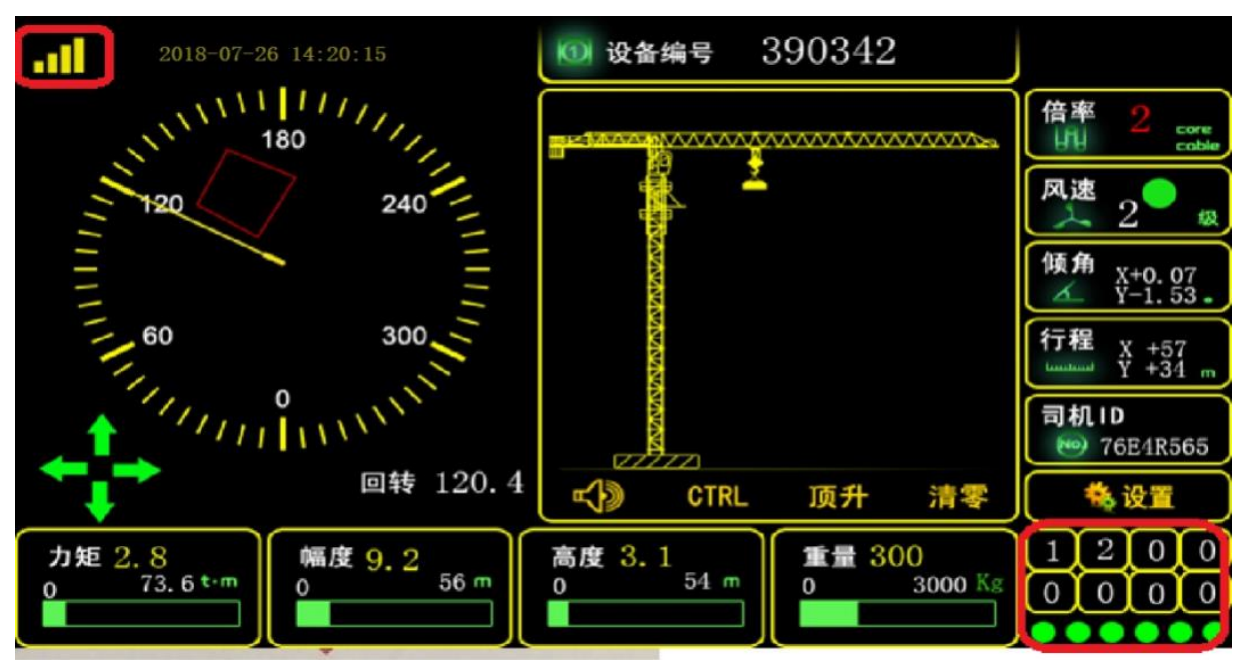

Figure 11. Operational status monitoring of tower cranes

\subsection{Environmental Supervision Subsystem}

The environmental supervision subsystem can monitor the construction site environment (including noise, dust, microclimate meteorological data management, and over-standard determination, over-standard alarm prompts and other functions). Figure 12 records the statistics of the dust monitoring alarms at the construction site, and can also view the monitoring data of the dust, PM2.5, PM10 and other indicators in the area during the specified time period, and summarize the statistics of the number of alarms at each site for the purpose of management. The construction site is one of the pollution sources that should be monitored by the city. The environmental monitoring subsystem can realize comprehensive analysis and feedback on environmental quality and monitoring data through large data and cloud computing.

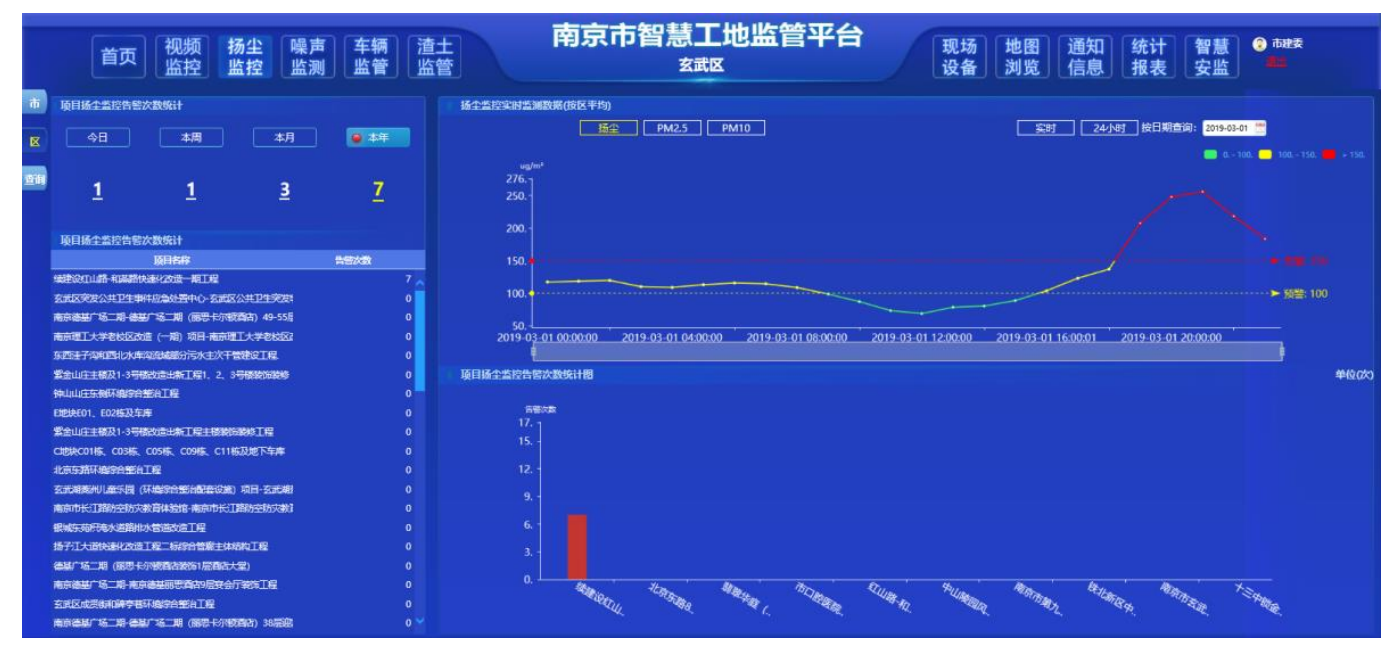

Figure 12. Real-time statistics of dust monitoring at the construction site 5.4 Cooperative Supervision Subsystem 
The cooperative supervision subsystem can deal with various types of events such as construction site quality, safety, environment and personnel (such as the processing, processing feedback, verification, and complete evaluation, and comprehensive query, statistical analysis and GIS-based maps of various aspects of construction site supervision management and other functions). Figure 13 records the comprehensive situation of a construction site, including on-site video surveillance images, real-time dust noise monitoring data, one-week site monitoring dynamics (dust monitoring, noise monitoring, vehicle non-flushing monitoring alarms, etc.) and basic information of the project, project progress, etc.

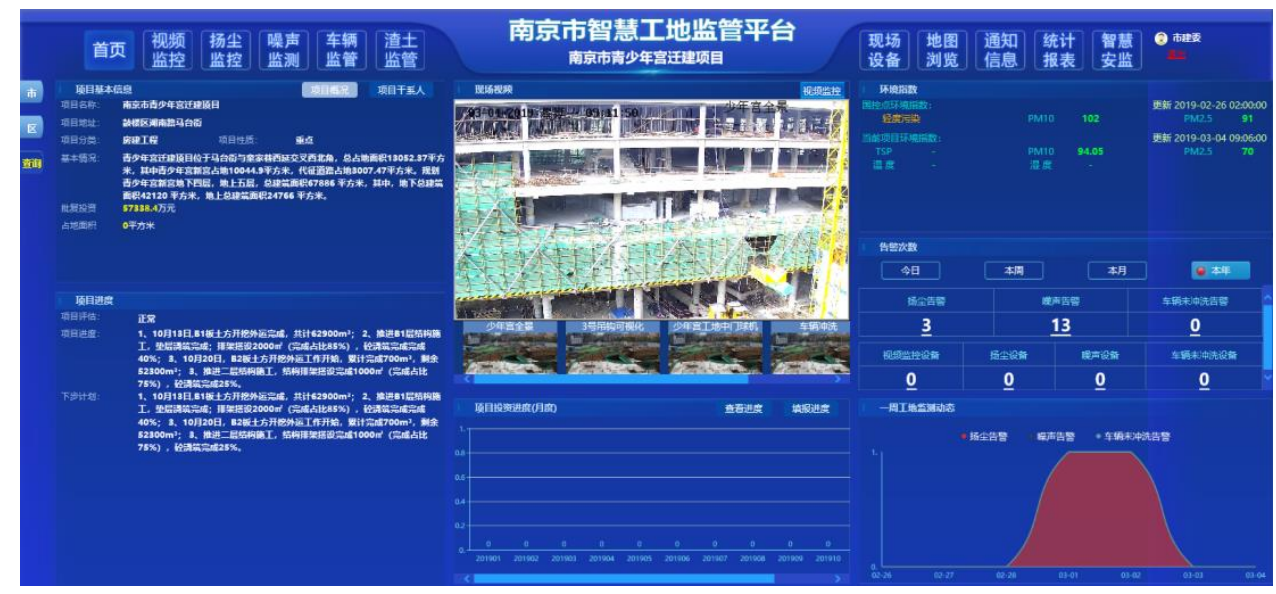

Figure 13. Comprehensive information inquiry on the construction site

\section{Smart City Management and Service}

Smart city management and service are directed toward "grid management and social service". It establishes city management and service event by means of answering questions from the public hotline in the call center, reporting problems found in the inspection process by using the APP system on smart phones and then based on the functions of collaborative management, work processing, supervision and supervision of workflow. To realize the classification and screening of all kinds of management incidents, to distribute and dispose in accordance with the functional division of labor, to arrange on-site inspection or return visits by special persons after the completion of the processing, and to use the comprehensive evaluation model of social management services, to achieve the supervision and evaluation of all aspects of urban management and social services, and to truly improve the operational efficiency and scientific level of urban management and social services. Smart city management and services cover a wide range of aspects, including safe city management, urban environmental health, social security prevention and control, people's livelihood security, ethnic religion, emergency disposal, and many other aspects.

\section{Intelligent landscape (garden) management}

The intelligent landscape (garden) management system mainly serves the planning, construction, and maintenance of urban green space, parks, and other landscaping resources, as well as the management of the maintenance of ancient and famous trees. It will scientifically and objectively analyze the site selection and greening layout of greening construction projects based on urban green space system planning. The system can calculate the green area, green space rate, green coverage and other greening indicators of the range according to the whole map or the designated area. The calculation results can be saved and viewed, as shown in Figure 14. 


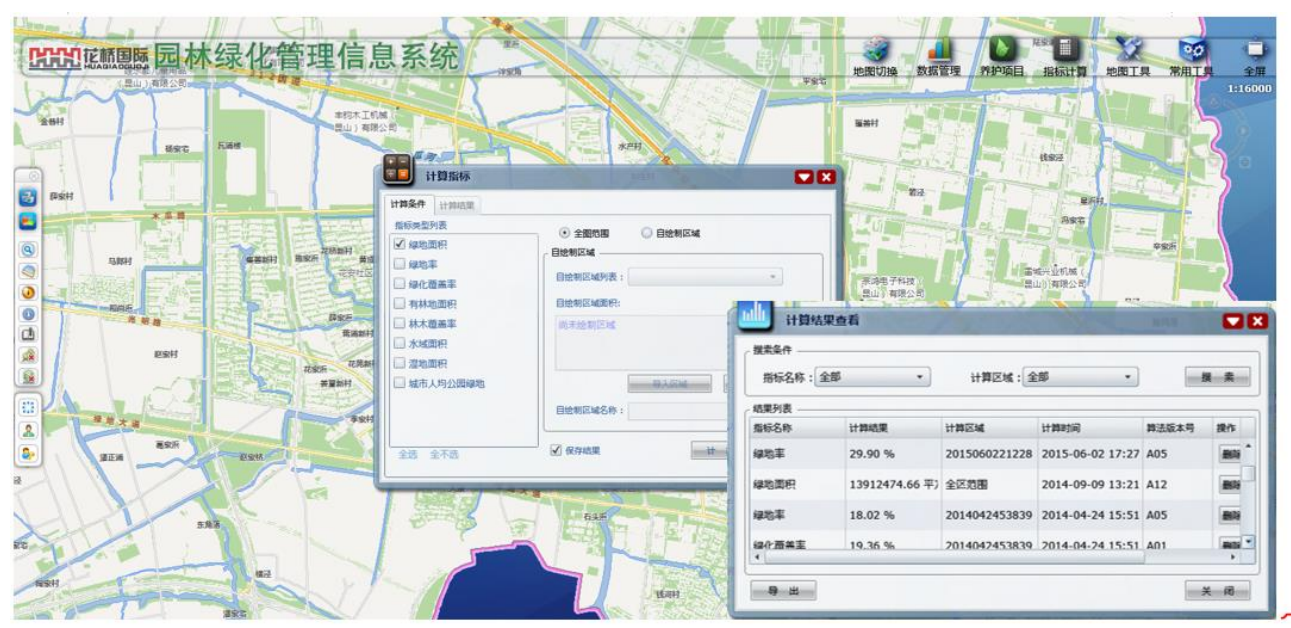

Figure 14. Calculation of landscaping indicators

\section{Smart water conservancy management}

The smart water conservancy management system can realize the comprehensive information management of water resources such as rivers, lakes, polders, dikes, sluices, pumping stations, and other water conservancy facilities. It can also realize the receiving and analysis of real-time monitoring data of hydrological stations, water level stations, meteorological stations, rainfall monitoring stations, water intake and sewage outlets of rivers and lakes. At the same time, it realizes the functions of river cross-section analysis, water resources spatial analysis, hydrometeorological dynamic monitoring, water conservancy project management, flood control, and drainage monitoring and dispatching. Figure 15 shows the vertical section of a river. From bottom to top, the elevation line of the river bed, the water level line at the time of measurement, the elevation line of the top of the left bank of the river and the elevation line of the top of the right bank of the river are marked respectively. Figure 16 is a statistical thematic map based on the total confluence area of general rivers, regional backbone rivers and important trans-regional rivers in different regions of the city. The system promotes the functions of flood control, drought resistance, disaster prevention and mitigation in cities, optimizes the allocation of water resources and makes efficient use of water resources, and makes wastewater treated and recycled.

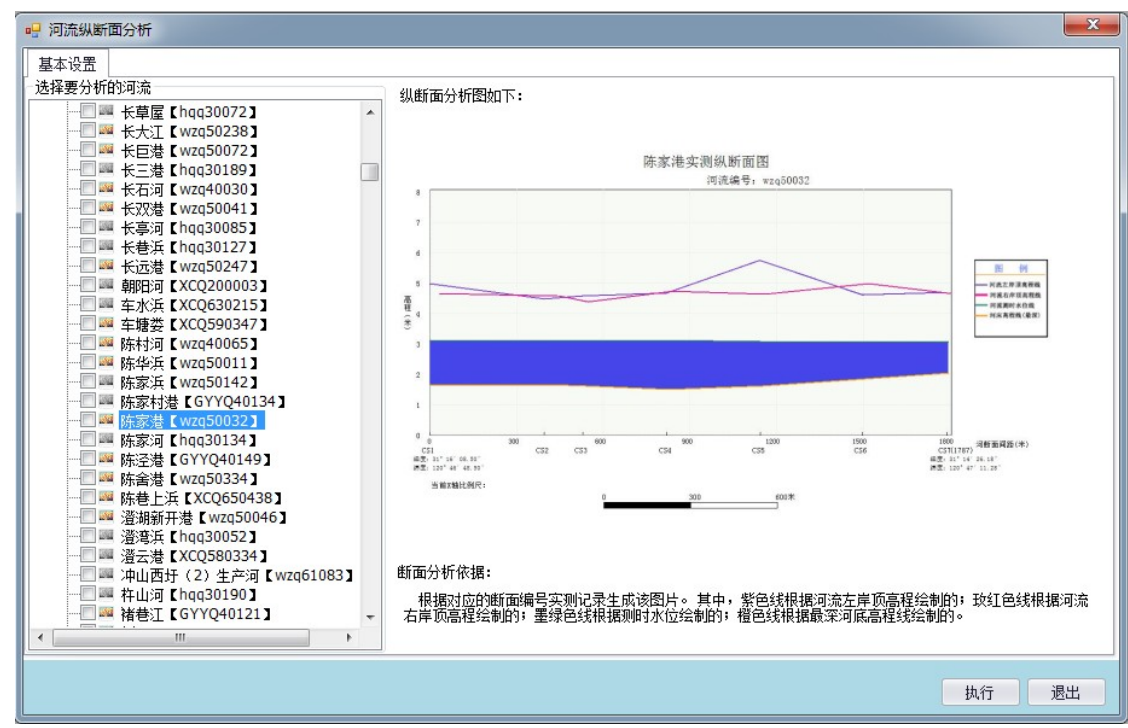

Figure 15. The vertical section of a river analysis 


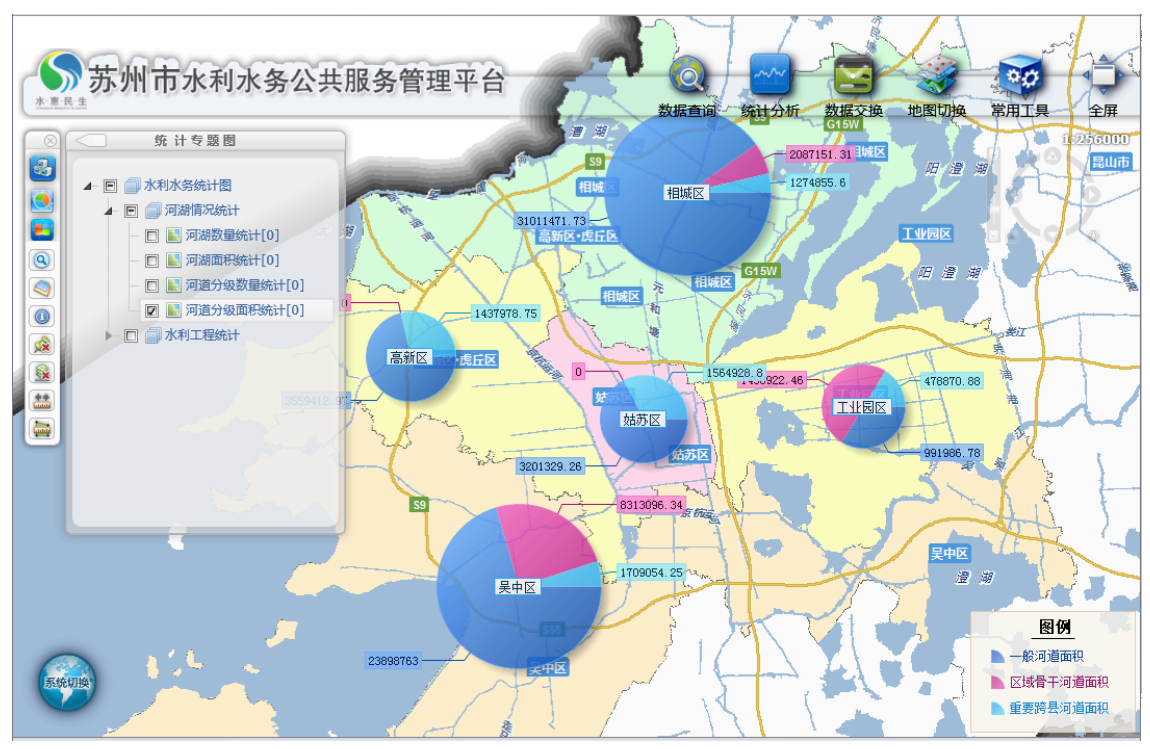

Figure 16. Thematic map of river area statistics in different regions

\section{Smart environmental management}

Smart environmental management makes full use of GIS, RS, GNSS, Internet of Things, mobile applications, cloud computing, drones and other information technologies, based on the concept of perception first, transmission as the basis, computing as the main, management as the basis, an environmental intelligent sensing network integrating satellite remote sensing and ground monitoring is constructed to realize the automation and intellectualization of environmental monitoring, establish environmental intelligent data center to realize safe storage and intelligent mining of massive data, develop environmental protection government application platform and environmental pollution prevention cooperation and exchange platform, provide technical support for international exchanges and cooperation in environmental protection daily business management and decision-making, and environmental pollution prevention and control technologies. Figure 17 shows the discovery of suspicious environmental illegal construction projects through satellite remote sensing image data (in case of illegal cases including unapproved construction, building large buildings only with the approval of small ones, construction in different places, etc.). The suspicious spots were under special supervision to find out potential illegal construction projects through on-site verification, audit, and review. Based on the environmental monitoring data, the government has formulated policies to vigorously promote the development of new energy automobile industry, encourage people to travel green and low-carbon, in order to ensure the air quality of the city. 


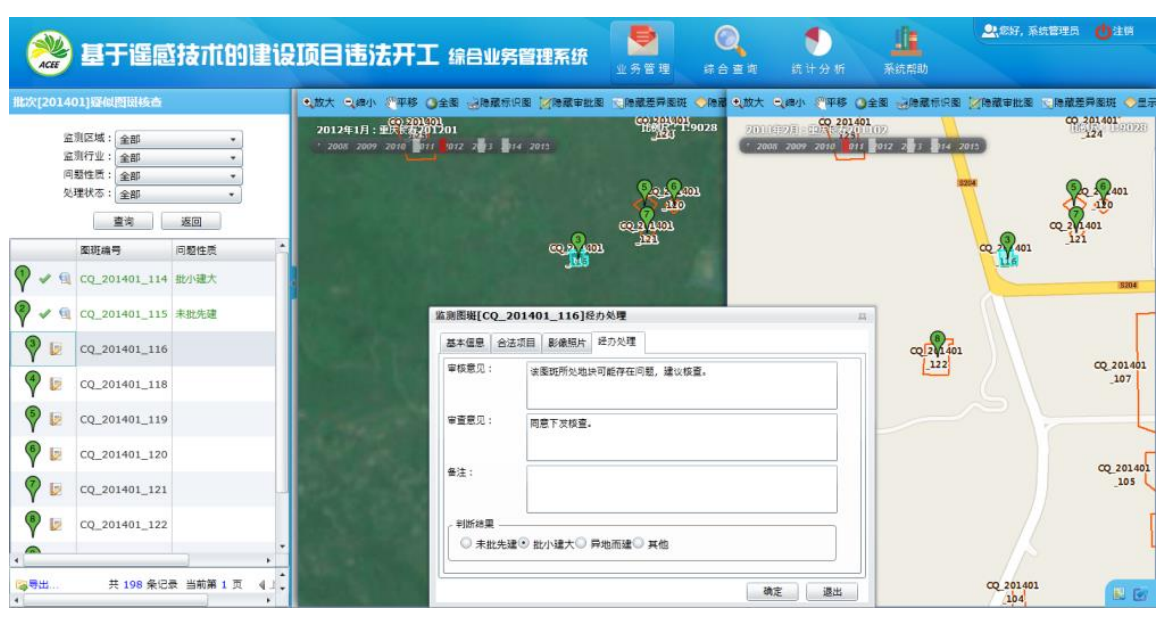

Figure 17. Using satellite remote sensing images to discover and supervise environmentally-friendly construction projects

\section{Conclusion}

At present, the construction of Chinese smart cities is accelerating. Digitalization is opening up an intelligent process characterized by deep mining of data and fusion applications. With the continuous enrichment of data resources and the rapid improvement of computing power, the application of data-driven intelligent new technologies is rapidly emerging. New technologies developed independently in China have played an increasingly important role in the construction of smart cities in China. The leading role of China's urban government departments promotes the interconnection, efficiency and intelligent development of various subsystems of urban management through the adoption of new information technology.

Chinese smart city construction needs to adapt to local conditions, adhere to the people-oriented concept, and use scientific and practical top-level design and planning. The construction of smart city is a systematic project. The integration and application of the geographic information sharing service platform and the control system such as urban planning, construction, and social management, as well as multi-industry and multi-department intelligent business information management systems such as landscaping, water conservancy, and environmental protection can improve the overall management level of the city. In order to promote new urban construction and sustainable urban development, it is necessary to make full use of GIS, RS, GNSS, Internet of Things, mobile applications, cloud computing, and other information technologies, integrate visualization technology, and constantly innovate smart city construction technology. The idea of smart city is becoming a reality by relying on the continuous application of new technologies.

\section{Acknowledgments}

The financial support from the Australian Research Council's Discovery Early Career Researcher Grant (DE170100165, DE 2017 R1) is acknowledged.

\section{References}

1. NU (United Nations). World Urbanization Prospects: The 2018 Revision. New York, United Nations Department of Economic and Social Affairs, Population Division. 2018

2. Xin Y. Analysis of urbanization based on human orientation: $<$ New national urbanization plan (2014-2020 years)>interpretations. Beijing, Xinhua Publishing House (in Chinese). 2015 
3. Cosgrave E. The smart city: challenges for the civil engineering sector. Proceedings of the Institution of Civil Engineers-Smart Infrastructure and Construction. 2018, 170 (4), 90-98, https://doi.org/10.1680/jsmic.17.00012.

4. Ogie R. I. ; Perez P.; Dignum V. Smart infrastructure: an emerging frontier for multidisciplinary research. Proceedings of the Institution of Civil Engineers - Smart Infrastructure and Construction. 2017, 170(1), 8-16, http://dx.doi.org/10.1680/jsmic.16.00002.

5. Qian Y. Wang M.; Yuan R. Visual analysis on evolution, hotspots, and frontier of smart city research--literature metrology based on web of science database. World Sci-Tech R \& D. 2018, (5), 1-9 (in Chinese).

6. Wan L; Nochta T; Schooling J. M. Developing a City-Level Digital Twin-Propositions and a Case Study[C]//International Conference on Smart Infrastructure and Construction 2019 (ICSIC) Driving data-informed decision-making. ICE Publishing, 2019, 187-194, https://doi.org/10.1680/icsic.64669.187

7. Jing C.; Du M.; Li S.; Liu S. Geospatial Dashboards for Monitoring Smart City Performance[J]. Sustainability. 2019, 11(20), 5648.

8. Mazzarino M.; Rubini L. Smart Urban Planning: Evaluating Urban Logistics Performance of Innovative Solutions and Sustainable Policies in the Venice Lagoon - the Results of a Case Study[J]. Sustainability. 2019, 11(17), 4580.

9. Angelidou M. Smart city policies: A spatial approach, Cities. 2014, 41, S3-S11. https://doi.org/10.1016/j.cities.2014.06.007

10. Yang L.; Li J.; Song L. Innovation of urban grid management and service based on smart city. Geomatics World. 2015, 22(4), 8-12 (in Chinese).

11. Peng H.; Zhang J.; Zhou Z.; Mendis P.; Han F.; Li Z.; Zhang D. Design and construction of the new library at China Agricultural University. Proceedings of the Institution of Civil Engineers-Civil Engineering. 2018, 172(5), 29-36, https://doi.org/10.1680/jcien.18.00033.

12. Peng H.; Gao D.; Zeng X.; Sofi M.; Zhou Z.; Li X. Using building information modeling for a commercial building in Beijing, China. Proceedings of the Institution of Civil Engineers-Civil Engineering. 2019, 172(5), 49-56, https://doi.org/10.1680/jcien.18.00035.

13. Shirowzhan S.; Tan W.; Sepasgozar S. Digital Twin and CyberGIS for Improving Connectivity and Measuring the Impact of Infrastructure Construction Planning in Smart Cities. ISPRS Int. J. Geo-Inf. 2020, 9, 240. 